\title{
Analisis Beban Kerja dan Kebutuhan Sumber Daya Manusia Petugas Rekam Medis Puskesmas Adan-adan Kabupaten Kediri
}

\section{Analysis of Workload and Human Resources Needs at the Adan-adan Health Center in Kediri District}

\author{
Hikmawan Suryanto \\ Program Studi D3 Rekam Medis dan Informasi Kesehatan, \\ Institut Ilmu Kesehatan Bhakti Wiyata Kediri \\ Jl. KH. Wachid Hasyim No 65 Kota Kediri \\ Email:hikmazwan.suryanto.hs@gmail.com
}

\begin{abstract}
Human resources are an important and vital component in an organization's operations. Quality health services can not be separated from the organization of a good medical record. In order to run well, sufficient medical records are needed. In the Adan-Adan Health Center, the number of patient visits from July 2018 to July 2019 was 16,828 people. Medical records officer only numbered 1 person. The research objective is to calculate the needs of human resources in the medical record unit using the ABK method. The design of this research is descriptive observational with case study approach. Respondents in this study were medical staff at the Adan-adan Health Center in Kediri Regency with a total of 1 person. The results of the study are that there is a shortage of human resources in the Adan-Adan Health Center medical record unit which should be 3, but totaling 1 person. Suggestions for Adan-Adan Health Center are employee recruitment needs to be done so that the number of medical records officers can be fulfilled
\end{abstract}

Keywords: Workload Analysis; Human Resource; Medical Records Officer; Adan-adan Health Center

\begin{abstract}
Abstrak
Sumber daya manusia merupakan komponen penting dan vital dalam operasional sebuah organisasi. Pelayanan kesehatan yang bermutu tidak terlepas dari penyelenggaraan rekam medis yang baik. Agar berjalan dengan baik, maka dibutuhkan sumber daya rekam medis yang cukup. Kunjungan pasien di Puskesmas Adan-adan pada periode Juli 2018 - Juli 2019 sebesar 16.828 orang. Petugas rekam medis hanya berjumlah 1 orang. Tujuan penelitian untuk menghitung kebutuhan sumber daya manusia di unit rekam medis menggunakan metode ABK. Desain penelitian ini yaitu observasional deskriptif dengan pendekatan case study. Responden dalam penelitian ini yaitu petugas rekam medis Puskesmas Adan-adan Kabupaten Kediri yang bejumlah 1 orang. Hasil penelitian yaitu terdapat kekurangan jumlah sumber daya manusia di unit rekam medis Puskesmas Adan-adan yang seharusnya berjumlah 3, namun saat ini berjumlah 1. Saran bagi Puskesmas Adan-adan yaitu perlu dilakukan rekrutmen pegawai agar jumlah petugas rekam medis dapat terpenuhi.
\end{abstract}

Kata Kunci: Analisis Beban Kerja, Sumber Daya Manusia, Petugas Rekam Medis, Puskesmas Adan-adan

\section{Pendahuluan}

Ketersediaan Sumber Daya Manusia di fasilitas pelayanan kesehatan, khususnya puskesmas menjadi sangat 
penting untuk memastikan pelayanan kesehatan berjalan dengan baik. Puskesmas merupakan ujung tombak pelayanan kesehatan di Indonesia. Puskesmas adalah unit pelaksana teknis Dinas Kesehatan Kabupaten/Kota yang bertanggung jawab menyelenggarkan pembangunan kesehatan di suatu wilayah kerja. Puskesmas mempunyai wewenang dan tanggung jawab atas pemeliharaan kesehatan masyarakat dalam wilayah kerjanya (Permenkes RI No 75, 2014). Secara umum, puskesmas harus memberikan pelayanan preventif, promotif, kuratif, dan rehabilitatif baik melalui upaya kesehatan perorangan (UKP) atau upaya kesehatan masyarakat (UKM).

Sumber daya manusia merupakan salah satu komponen penting dalam organisasi, termasuk puskesmas. Keberadaan sumber daya manusia harus direncanakan dan dikelola dengan baik. Proses perencanaan sumber daya manusia adalah suatu cara yang digunakan untuk menetapkan tujuan dan pedoman dalam pelaksanaan organisasi (Marlina, 2015). Jumlah pegawai yang melebihi kapasitas atau kurang dari kebutuhan organisasi menunjukkan bahwa organisasi kurang baik dalam mengelola sumber daya manusia. Menurut Wardanis (2018), tujuan dari perencanaan sumber daya manusia yaitu menentukan kualitas dan kuantitas pegawai yang akan mengisi suatu jabatan dalam organisasi, pengembangan, pemeliharaan, kompensasi, pemberhentian pegawai, menjamin ketersediaan sumber daya manusia masa kini maupun masa depan, tidak terjadinya tumpang tindih dan kelebihan pegawai dalam pelaksaan organisasi.

Pelayanan kesehatan yang prima tidak lepas dari penyelenggaraan rekam medis yang bermutu. Agar penyelenggaraan rekam medis bermutu, maka diperlukan tenaga kerja yang bekerja sesuai dengan kompetensinya. Selain kompetensi, jumlah tenaga juga penting untuk menunjang pelayanan, baik dari segi waktu penyediaan berkas rekam medis maupun beban kerja pegawai. Menurut Talib (2018), analisis beban kerja pegawai rekam medis bertujuan untuk mencapai produktivitas kerja yang optimal dengan pendayagunaan pergawai sesuai job description.

Berdasarkan hasil observasi, petugas rekam medis di Puskesmas Adan-adan hanya berjumlah 1 orang. Jumlah kunjungan pasien periode Juli 2018 - Juli 2019 sebesar 16.828. Kunjungan pasien perhari rata-rata berjumlah 60 hingga 70 orang. Selain itu, pasien harus mengantri lama dan tempat duduk yang disediakan puskesmas tidak mencukupi. Untuk membantu petugas rekam medis, puskesmas memberdayakan pegawai lain untuk diperbantukan di bagian tempat pendaftaran pasien. Menurut Rakhmawati (2016), kekurangan jumlah petugas rekam medis, akan menyebabkan petugas kewalahan, sehingga beban kerja petugas tinggi. Sedangkan menurut Sartika (2016), petugas rekam medis yang kewalahan dengan beban kerjanya, akan menyebabkan kurang nyaman dalam bekerja, sehingga berdampak pada stres kerja. Berdasarkan uraian latar belakang masalah diatas, penelitian ini bertujuan untuk menganalisis beban kerja dan mengetahui kebutuhan sumber daya manusia unit rekam medis Puskesmas Adan-adan Kabupaten Kediri.

\section{Metode}

Desain penelitian ini yaitu deskriptif dengan pendekatan case study. Responden dalam pe nelitian ini yaitu petugas rekam medis Puskesmas Adan- 
adan Kabupaten Kediri yang bejumlah 1 orang. Instrumen yang digunakan dalam penelitian ini adalah lembar obsevasi, lembar wawancara, dan stopwatch. Teknik pengumpulan data yaitu dengan wawancara dan observasi. Teknik analisis data menggunakan metode analisis beban kerja, kemudian dijelaskan secara deskriptif.

\section{Hasil dan Pembahasan}

Pelayanan rekam medis di Puskesmas Adan-adan Kabupaten Kediri dimulai pada saat pasien akan didaftar. Setelah pasien didaftar, kemudian data pasien ditulis di buku register dan diinput di SIMPUS (Sistem Informasi Manajemen Puskesmas). Setelah itu, dokumen rekam medis didistribusikan ke poli. Setelah pelayanan poli selesai, petugas poli mengembalikan dokumen rekam medis pasien ke petugas rekam medis. Kemudian, petugas rekam medis menganalisis kelengkapan pencatatan dokumen. Apabila terdapat ketidaklengkapan dokumen, maka dokumen rekam medis dikembalikan lagi pada petugas poli. Jika sudah lengkap, maka petugas rekam medis mengurutkan dan menata formulir dengan rapi lalu dikembalikan ke rak filing.

Berdasarkan hasil pengamatan, petugas rekam medis sering dibantu oleh pegawai dari bagian lain. Petugas rekam medis harus merangkap tugas menjadi petugas TPP, kemudian mengkoding, assembling, distribusi dokumen rekam medis ke poli, dan mengembalikan dokumen rekam medis ke rak filing. Keterbatasan jumlah sumber daya manusia menjadikan petugas rekam medis memiliki beban kerja yang melebihi kapasitas. Beban kerja berpengaruh terhadap produktivitas kerja. Menurut Fadila (2019), penambahan tenaga kerja akan menambah produktivitas dari petugas rekam medis.

Berikut merupakan hasil dari analisis beban kerja petugas rekam medis Puskesmas Adan-adan menggunakan metode ABK yang bersumber dari Permenkes RI Nomor 53 Tahun 2012 Tentang Pedoman Pelaksanaan Analisis Beban Kerja di Lingkungan Kementrian Kesehatan. Langkah-langkah dalam analisis beban kerja adalah sebagai berikut:

a. Menetapkan fasilitas kesehatan dan jenis SDMK (Sumber Daya Manusia Kesehatan). Fasilitas kesehatan yaitu UPTD Puskesmas Adan-adan Kabupaten Kediri. Jenis SDMK adalah petugas rekam medis.

b. Menetapkan WKT (Waktu Kerja Tersedia). Waktu kerja tersedia adalah waktu yang tersedia untuk masingmasing kategori SDM yang bekerja selama kurun waktu satu tahun. Berdasarkan Keputusan Presiden RI Nomor 68 Tahun 1995 tentang Hari Kerja Dilingkungan Lembaga Pemerintah telah ditentukan jam kerja instansi pemerintah yaitu 37 jam 30 menit per minggu, baik untuk 5 (lima) hari kerja ataupun 6 (enam) hari kerja. Kebijakan 5 (lima) hari atau 6 (enam) hari kerja sesuai yang ditetapkan kepala daerah masing-masing. Berdasarkan Peraturan Badan Kepegawaian Negara Nomor 19 Tahun 2011 tentang Pedoman Umum Penyusunan Kebutuhan Pegawai Negeri Sipil, Jam Kerja Efektif (JKE) yaitu 1200 jam per tahun. Menurut Permen PAN-RB No. 26 tahun 2011 tentang Pedoman Perhitungan Jumlah Kebutuhan Pegawai Negeri Sipil Yang Tepat Untuk Daerah, Jam Kerja Efektif (JKE) sebesar 1200 jam per tahun atau 72000 menit per tahun baik 5 hari kerja atau 6 hari kerja. 
c. Menetapkan Komponen Beban Kerja

waktu di Puskesmas Adan-adan dan Norma Waktu. Berikut penetapan komponen beban kerja dan norma

Kabupaten Kediri

Tabel 1. Beban Kerja dan Norma Waktu

\begin{tabular}{|c|c|c|c|}
\hline No. & Jenis Tugas & Kemampuan beban kerja & Norma waktu \\
\hline \multirow[t]{8}{*}{1.} & \multirow[t]{8}{*}{ Tugas Pokok } & Pendaftaran pasien & 2 menit \\
\hline & & Pengambilan DRM & 1 menit \\
\hline & & Menulis buku register & 2 menit \\
\hline & & Menginput data ke SIMPUS & 1 menit \\
\hline & & Mendistribusikan DRM & 2 menit \\
\hline & & Checklist DRM kembali ke poli & 1 menit \\
\hline & & $\begin{array}{l}\text { Assembling dan penelitian ketidaklengkapan } \\
\text { DRM }\end{array}$ & 2 menit \\
\hline & & Pengembalian kembali DRM ke rak filing & 1 menit \\
\hline \multirow[t]{6}{*}{2.} & \multirow[t]{6}{*}{ Tugas penunjang } & Rapat & $8 \mathrm{jam} / \mathrm{bln}$ \\
\hline & & & $=8 \times 12$ \\
\hline & & & $=96 \mathrm{jam} / \mathrm{thn}$ \\
\hline & & & $=96 \times 60$ menit \\
\hline & & & $=5760$ menit $/$ thn \\
\hline & & Bimbingan PKL & $\begin{array}{l}4 \mathrm{jam} / \text { tahun } \\
=4 \times 60 \text { menit }\end{array}$ \\
\hline
\end{tabular}

Berdasarkan tabel diatas dapat diketahui bahwa terdapat 8 tugas pokok dan 2 tugas penunjang dari petugas rekam medis di Puskesmas Adan-adan. Norma waktu tugas pokok dihitung d. Menghitung

Standar

Tabel 2. Standar Beban Kerja

\begin{tabular}{lccc}
\hline \multicolumn{1}{c}{ Kegiatan } & $\begin{array}{c}\text { Norma } \\
\text { waktu }\end{array}$ & $\begin{array}{c}\text { WKT } \\
\text { (menit) }\end{array}$ & $\begin{array}{c}\text { SBK } \\
\text { (WKT/Norma } \\
\text { waktu) }\end{array}$ \\
\hline Pendaftaran pasien & 2 & 72000 & $72000: 2=36000$ \\
\hline Pengambilan DRM & 1 & 72000 & $72000: 1=72000$ \\
\hline Menulis buku register & 2 & 72000 & $72000: 2=36000$ \\
\hline Input data ke SIMPUS & 1 & 72000 & $72000: 1=72000$ \\
\hline Distribusi DRM & 2 & 72000 & $72000: 2=36000$ \\
\hline Checklist DRM kembali ke poli & 1 & 72000 & $72000: 1=72000$ \\
\hline Assembling & 2 & 72000 & $72000: 2=36000$ \\
\hline Pengembalian DRM ke rak filing & 1 & 72000 & $72000: 1=72000$ \\
\hline
\end{tabular}

e. Menghitung Standar Tugas

Penunjang (STP) dan Faktor Tugas

Penunjang (FTP). Terdapat 2 tugas penunjang yang ditugaskan kepada petugas rekam medis di Puskesmas Adan-adan.

1) Waktu kegiatan :
a) Bimbingan $\mathrm{PKL}=$
240 menit/tahun
b) Rapat $=5760$ menit $/$ tahun

menggunakan stopwatch. Sedangkan norma waktu tugas penunjang, didapatkan dari hasil wawancara kepada petugas rekam medis.

Beban

Kerja. 


$$
=0,33 \%+8 \%=8,33 \%
$$

3) Standar Tugas Penunjang (STP)

$$
=(1 /(1-\mathrm{FTP} / 100))
$$

f. Menghitung kebutuhan SDMK (Sumber Daya Manusia Kesehatan)

Kebutuhan SDMK = Capaian (1 thn) / Standar beban kerja x STP

Capaian satu tahun didapat dari perhitungan jumlah pasien yang berkujung ke Puskesmas Adan-adan Kabupaten Kediri dimulai dari bulan Juni 2018 sampai dengan bulan Juli 2019. Data

$$
\begin{aligned}
& =(1 /(1-8,33 / 100) \\
& =1 / 0,91 \\
& =1,09
\end{aligned}
$$

tersebut didapat dari buku register kunjungan loket. Buku tersebut berisi jumlah pasien pada setiap kali kunjungan. Berdasarkan data sekunder dari buku register, kunjungan loket di Puskesmas Adan-adan Kabupaten Kediri sejumlah 16.828 pada periode Juni 2018 hingga Juli 2019. Rata-rata jumlah kunjungan perhari yaitu 60 pasien.

Tabel 3. Kebutuhan Sumber Daya Manusia Kesehatan Tugas Pokok

\begin{tabular}{lccc}
\hline \multicolumn{1}{c}{ Komponen beban kerja/kegiatan } & Capaian $\mathbf{1}$ th & SBK & Kebutuhan SDMK \\
\hline Pendaftaran pasien & 16.828 & 36000 & $16.828 / 36000 \times 1,09=0,50$ \\
\hline Pengembalian DRM & 16.828 & 72000 & $16.828 / 72000 \times 1,09=0,25$ \\
\hline Menulis buku register & 16.828 & 36000 & $16.828 / 36000 \times 1,09=0,50$ \\
\hline Menginput data ke SIMPUS & 16.828 & 72000 & $16.828 / 72000 \times 1,09=0,25$ \\
\hline Mendistribusikan DRM & 16.828 & 36000 & $16.828 / 36000 \times 1,09=0,50$ \\
\hline Checklist DRM kembali ke poli & 16.828 & 72000 & $16.828 / 72000 \times 1,09=0,25$ \\
\hline $\begin{array}{l}\text { Assembling dan penelitian } \\
\text { ketidaklengkapan DRM }\end{array}$ & 16.828 & 36000 & $16.828 / 36000 \times 1,09=0,50$ \\
\hline Pengembalian kembali DRM ke rak filing & 16.828 & 72000 & $16.828 / 72000 \times 1,09=0,25$ \\
\hline
\end{tabular}

JKT (Jumlah Ketentuan Tenaga) Tugas pokok $=3$

Standar Tugas Penunjang (Hasil dari langkah ke-5) = 1,09

Total Kebutuhan SDMK Petugas Rekam Medis di Puskesmas Adan-adan yaitu $=(\mathrm{JKT} \times \mathrm{STP})$

$=3 \times 1,09$

\section{$=3,27($ dibulatkan menjadi 3$)$}

g. Rekapitulasi Kebutuhan SDMK (Sumber Daya Manusia Kesehatan) berdasarkan metode ABK (Analisis Beban Kerja) di Puskesmas Adanadan Kabupaten Kediri

Tabel 4. Rekapitulasi SDMK Berdasarkan Metode ABK

\begin{tabular}{ccccc}
\hline Jenis SDMK & $\begin{array}{c}\text { Jumlah SDMK } \\
\text { saat ini }\end{array}$ & $\begin{array}{c}\text { Jumlah SDMK } \\
\text { yang } \\
\text { seharusnya }\end{array}$ & $\begin{array}{c}\text { Kesenjangan } \\
\text { SDMK }\end{array}$ & Keadaan \\
\hline Petugas Rekam Medis & 1 & 3 & $3-1=2$ & Kurang
\end{tabular}

Berdasarkan hasil perhitungan analisis beban kerja, didapatkan hasil bahwa tenaga rekam medis di Puskesmas Adan-adan masih kurang. Saat ini, di Puskesmas Adan-adan
Kabupaten Kediri hanya ada 1 petugas rekam medis. Berdasarkan hasil perhitungan beban kerja, seharusnya Puskesmas Adan-adan memiliki 3 petugas rekam medis. Hal tersebut 
mengakibatkan beban kerja petugas rekam medis menjadi over kapasitas. Hal ini sesuai dengan penelitian Cahyaningrum (2018) yang mengatakan bahwa kurangnya SDM membuat beban kerja petugas rekam medis menjadi tinggi. Menurut Alfianto (2015), beban kerja petugas rekam medis mengalami peningkatan seiring bertambahnya jumlah kunjungan pasien, sehingga mempengaruhi produktivitas kerja. Perencanaan kebutuhan sumber daya penting dilalukan agar pelayanan menjadi bermutu dan prima. Menurut Hasibuan (2005) perencanaan sumber daya manusia adalah merencanakan tenaga kerja agar sesuai dengan kebutuhan organisasi serta efektif dan efisien dalam menbantu mewujudkan tujuan yang akan dicapai. Menurut Sidiq (2014), beban kerja petugas rekam medis yang tinggi, dapat menyebabkan produktifitas kerjanya menjadi rendah.

Menurut Permenkes RI Nomor 75 Tahun 2014 Tentang Pusat Kesehatan Masyarakat, puskesmas berfungsi menyelenggarakan upaya kesehatan masyarakat (UKM) dan Upaya Kesehatan Perorangan (UKP) tingkat pertama. Oleh karena itu, perlu untuk merencanakan kebutuhan sumber daya manusia agar pelayanan di puskesmas dapat berjalan dengan baik. Jika pelayanan puskesmas baik, maka dapat meningkatkan mutu puskesmas. Pasien mendapatkan pelayanan prima dan cepat, sehingga tidak banyak waktu yang terbuang untuk antri. Hal ini sesuai dengan penelitian Nurhayati (2017) yang mengatakan bahwa perencanaan kebutuhan tenaga kerja kesehatan berdasarkan beban pekerjaan khususnya rekam medis dilakukan demi tercapainya pelayanan yang maksimal. Menurut Yuliani (2013), dampak dari kurangnya sumber daya manusia di unit rekam medis, akan menyebabkan waktu ketersediaan dokumen rekam medis menjadi lebih lama. Oleh karena itu, Puskesmas Adanadan perlu melakukan rekrutmen petugas rekam medis.

\section{Simpulan dan Saran}

\section{Simpulan}

Berdasarkan hasil perhitungan analisis beban kerja menggunakan metode ABK, jumlah tenaga rekam medis di Puskesmas Adan-adan Kabupaten Kediri masih kurang. Seharusnya, jumlah petugas rekam medis berjumlah 3 orang. Namun, di Puskesmas Adan-adan Kabupaten Kediri hanya ada 1 orang. Oleh karena itu, jumlah petugas rekam medis masih kurang 2 orang

\section{Saran}

Puskesmas Adan-adan Kabupaten Kediri perlu melakukan rekrutmen petugas rekam medis agar beban kerja petugas rekam medis tidak melebihi kapasitas dan dapat memberikan pelayanan dengan baik, sehingga antrian pasien menjadi lebih efisien.

\section{Ucapan Terima Kasih}

Terima kasih disampaikan kepada Kepala Puskesmas Adan-adan, drg. Priyatno Santoso yang telah memberikan informasi dan izin dalam penelitian ini. Terima kasih juga kepada Kabag. Rekam Medis Puskesmas Adan-adan, Novi Inayah Amd. Kes yang telah bersedia menjadi responden dalam penelitian ini.

\section{Daftar Pustaka}

Alfianto, Lucky. 2015. Analisa Perkiraan Jumlah SDM Rekam Medik di Unit Filing Dengan Metode WISN (Workload Indicator Staff Need) di RSUD Kabupaten Wonogiri Tahun 2014. Indonesian Journal On Medical Science, Vol 2, Ed 1, hal 69 - 73

Cahyaningrum, Nopita. 2018. Tinjauan Beban Kerja Dan Kebutuhan 
Sumber Daya Manusia Unit Rekam Medis Berdasarkan Metode WISN Di RSUD Banyu Bening Boyolali Tahun 2018. Jurnal Infokes Universitas Duta Bangsa, Vol 8, Ed 2, hal $40-54$

Fadila, Rizki. 2019. Analisis Kebutuhan Sumber Daya Manusia Rekam Medis di Unit Filing. Jurnal Rekam Medis dan Informasi Kesehatan, Vol 2, Ed 1, hal 48 - 55

Hasibuan, S.P Malayu. 2005. Manajemen Sumber Daya Manusia. Edisi Revisi. Jakarta : Bumi Aksara

Keputusan Presiden RI Nomor 68 Tahun 1995 Tentang Hari Kerja Dilingkungan Lembaga Pemerintah

Marlina, L. 2015. Manajemen Sumber Daya Manusia (SDM) dalam Pendidikan. Istinbath, Vol 15, hal 123-139.

Nurhayati. 2017. Perangkat Lunak Estimasi Kebutuhan Tenaga Kerja Rekam Medis. Seminar Nasional Teknologi Informasi dan Bisnis (SENATIB), hal 115 - 124

Peraturan Menteri PAN-RB No. 26 Tahun 2011 tentang Pedoman Perhitungan Jumlah Kebutuhan Pegawai Negeri Sipil Yang Tepat Untuk Daerah

Peraturan Badan Kepegawaian Negara Nomor 19 Tahun 2011 tentang Pedoman Umum Penyusunan Kebutuhan Pegawai Negeri Sipil

Peraturan Menteri Kesehatan RI Nomor 53 Tahun 2012 Tentang Pedoman Pelaksanaan Analisis Beban Kerja di Lingkungan Kementrian Kesehatan
Permenkes RI Nomor 75 Tahun 2014 Tentang Pusat Kesehatan Masyarakat

Rakhmawati, Fitria. 2016. Analisis Kebutuhan Petugas Rekam Medis Berdasarkan Beban Kerja di Instalasi Rekam Medis RS Aisyiah Muntilan. Jurnal Kesehatan Vokasional, Vol 1, Ed 1, hal 1-8

Sartika, Dewi. 2016. Gambaran Stres Kerja Pegawai Bagian Rekam Medis Rumah Sakit Bhakti Wiratamtama Semarang. Unnes Journal of Public Health, Vol, 5, Ed 3, hal 186 - 194

Sidiq, Rapitos. 2014. Distribusi Tenaga Rekam Medis Pada Puskesmas di Kota Langsa Kabupaten Pidie dan Simeulue Provinsi Aceh Tahun 2013. Jurnal Manajemen Informasi Kesehatan Indonesia, Vol 2, Ed 1, hal $1-7$

Talib, Thabran. 2018. Analisis Beban Kerja Tenaga Filing Rekam Medis (Studi Kasus Rumah Sakit Ibu dan Anak Bahagia Makassar). Jurnal Manajemen Informasi Kesehatan Indonesia, Vol 6, Ed 2, hal 123 - 128

Wardanis, Dwi Trisna. 2018. Analisis Beban Kerja Tenaga Rekam Medis Rumah Sakit Bedah Surabaya Menggunakan Metode FTE. Jurnal Administrasi Kesehatan Indonesia, Vol 6, Ed 1, hal 53 - 60

Yuliani, Novita. 2013. Analisis Kebutuhan Tenaga Kerja Rekam Medis Bagian Pendaftaran Pasien Rawat Jalan di UPT Puskesmas Pucang Sawit Surakarta. Jurnal Ilmiah Rekam Medis dan Informasi Kesehatan, Vol 3, Ed 2, hal 33 - 39 